\title{
Are School Oral Health Programs Effective in Changing Dental Health and Health Behavior of Children; an Observational Study
}

\author{
Sarah Ahmed Bahammam ${ }^{1}$ \\ ${ }^{1}$ Diplomate of the American Board of Pediatric Dentistry, Assistant Professor, Department of Pediatric Dentistry \\ and Orthodontics, Collage of Dentistry, Taibah University, Medina, Kingdom of Saudi Arabia \\ Correspondence: Sarah Ahmed Bahammam BDS, MSD, CAGS, DScD, FRCD(C), Diplomate of the American \\ Board of Pediatric Dentistry, Assistant Professor, Department of Pediatric Dentistry and Orthodontics, Collage \\ of Dentistry, Taibah University, Universities Road, P. O. Box 344, Medina, Kingdom of Saudi Arabia. Tel: \\ 966-56-401-3000; Fax: 966-486-1172. E-mail: sbahammam@taibahu.edu.sa
}

Received: July 7, 2020 Accepted: July 22, 2020 Online Published: July 23, 2020

doi:10.5539/gjhs.v12n10p25 URL: https://doi.org/10.5539/gjhs.v12n10p25

\begin{abstract}
Background: Oral health issues are recorded to be growing among children due to either insufficient knowledge or ineffective oral health care. The study investigated the effectiveness of the school oral health $(\mathrm{OH})$ program for changing dental health and health behavior among the students in Saudi Arabia.
\end{abstract}

Methods: This cross-sectional design study followed STROBE (strengthening the reporting of observational studies in epidemiology) guidelines to include 348 female primary children in Madinah, Saudi Arabia. These were equally divided into three groups; i.e., teacher delivered oral health program, dentist delivered oral health program, and lastly control group. Data was collected through a close-ended questionnaire, and were analyzed through descriptive statistics and ANOVA.

Results: Findings of the study showed improved $\mathrm{OH}$ status, better $\mathrm{OH}$ knowledge, behavior and practices among children. Self-evaluation results showed that the teachers conducted education program was more effective, then the dentists conducted education program. Also, oral health-related quality of life (OHRQoL) score was found high for the psychological aspect of the children.

Conclusion: The effectiveness of the school oral health program for changing dental health and health behavior among the students was better.

Keywords: dental health, health behavior of children, madinah, observational study, Saudi Arabia, school oral health programs

\section{Introduction}

Oral diseases are recognized as a major health problem globally. The World Health Organization (WHO) has documented that about 90 percent of the school-children are affected by dental caries (Adair, Burnside, \& Pine, 2013; Nguyen, et al., 2016; WHO, 2020). Zhang et al. (2015) and Nguyen et al. (2016) reports that in East Asia, caries prevalence for the school children concerning their DMFT (decayed, missing, and filled teeth) index score was higher from 2005 to 2015, in contrast to other regions (Nguyen et al., 2016; Zhang et al., 2015). Most studies report that school children's oral health is affected by various factors including oral hygiene, dental care education, diet as well as guardians/parents' oral health knowledge (de Castilho et al. 2013; Nguyen et al., 2016).

WHO identifies oral disease as the common form of non-communicable diseases, which affect an individual throughout his/her life, resulting in its discomfort, pain, and disfigurement (Deinzer et al., 2019; Nguyen et al., 2016; WHO, 2020). Understanding that untreated dental caries can lead to negative consequences is important, particularly in school children. The negative consequence as reported in previous studies includes difficulty in eating, dental pain, inadequate sleep, poor appearance, low concentration as well as absence from the school (BaniHani et al., 2018; CDC, 2020; WHO, 2020). These children might also be vulnerable to social rejection, where they are teased and excluded socially due to various defects, including visible defects, bad odors, or impeded articulation (Craig, Baker, \& Rodd, 2015). To overcome these negative consequences, studies have suggested to include proper oral health education, which assists in overcoming the unpleasant psychological, somatic, and social experiences (Deinzer et al., 2019). As health behavior is carried regularly, it is necessary to 
educate children concerning their take up of their oral health responsibilities.

Concerning Saudi Arabia, children's oral health hygiene is found to be poor, where caries was reported to be present in 90 percent of the children (Alsubaie, 2019). An earlier study by Al-Banyan et al., (2000) found its prevalence to be 94.4 percent in children. While Farooqi et al. (2015) reported its prevalence to be 78 percent for 6 to 9 years and 68 percent for 10 to 12 years. Whereas, Al-Rafee, et al (2019) found the prevalence of caries to be 85.77 percent among children in the six years' group, while 64.98 percent in the 12 years and 71.35 percent in 15 years. Studies reveal that this may be due to their inadequate brushing habits, which leads to plaque formation, accounting for dental caries (Alswat et al., 2016; Tinanoff, 2017). Alsubaie (2019) concludes that oral hygiene habits can be developed in children.

Various studies have suggested the implementation of oral health programs for the primary children; however, its impact has been evaluated by few studies (Nguyen et al., 2016; Villanueva-Vilchis, Aleksejūnienè, \& López-Núñez, 2019). The only study that evaluated the effectiveness of such programs on the oral health of the school children is Halawany et al. (2018). However, the findings of the study remain limited due to its restriction to Riyadh. Thereby, the present study aims to examine whether the school oral health programs are effective in changing dental health and health behavior of female children in Madinah, Saudi Arabia. The findings are assumed to assist in devising and adopting measures that help improve oral health care in children.

\section{Methods}

\subsection{Study design}

This cross-sectional design study followed the STROBE (strengthening the reporting of observational studies in epidemiology) guidelines. The STROBE guidelines are applied in an observational study, as these assist to present the results in a clear way as per the initially determined plan (WMA, 2019). This study was conducted from Feb 2020 to March 2020 in primary schools in Madinah, Saudi Arabia.

\subsection{Study Population and Procedure}

The study population constitutes primary school children in Madinah, Saudi Arabia. The sample of the study was randomly selected from primary schools in Saudi Arabia. From the study sample, the value of the error of margin was 0.5 ; the confidence interval was 95 percent, and an estimated population of primary female students in Madinah as 20,000. The population size was estimated as the number is less likely to change for a population above 20,000 $(\mathrm{n}=377)$ (Hazra \& Gogtay, 2016; Suresh, 2014). Thereby, the required sample size considered should be a minimum of 377 . With regard to the drop-out rate, the final sample that is considered is to be 380 students. Among the distributed 380 questionnaires, only 348 were completed and complied.

Initially, these students were numbered with the use of computer-generated simple random numbering. These children were aged between 8 to 10 years. These were then equally divided into three groups and exposed to different or no school-based oral health prevention programs. Such as one group was delivered a school-based oral health prevention program by teachers, and one by dentists, whereas one group was not provided with an oral health prevention program. The study has assessed the school-based oral health prevention program delivered by the dentist included a PowerPoint presentation only. While in the oral health prevention program delivered by a teacher, PowerPoint, along with different supporting material (charts, activities, and videos), was used. Ethical approval was acquired from Institutional Review Board (IRB).

This research was also held in accordance with the Helsinki Declaration. This declaration is an ethical policy statement issued by the WMA (2019). It deals with medical researches that involve human subjects concerning the identifiable material and data to be researched. It requires the researcher to ensure the safety of the study participants. ${ }^{19}$ Further, a written consent form was acquired from the parents/guardians of the children.

\subsection{Data Collection}

For analyzing the effectiveness of oral health program in schools on oral health $(\mathrm{OH})$ and behavior of children, information concerning their $\mathrm{OH}$ knowledge, behavior as well as $\mathrm{OH}$ self-evaluation was gathered. This was done using a questionnaire that collected information concerning their oral health $(\mathrm{OH})$ status and second oral health quality of life (OHRQoL). The $\mathrm{OH}$ status was further sub-divided into three sections, i.e., $\mathrm{OH}$ knowledge, $\mathrm{OH}$ behavior, and $\mathrm{OH}$ self-evaluation. The $\mathrm{OH}$ knowledge comprised six closed-ended questions, and $\mathrm{OH}$ behavior included six close-ended questions. Whereas, concerning $\mathrm{OH}$ self-evaluation, children were asked whether they had the dental disease or not, where two close-ended questions assessed the way students evaluated their oral health. All the items in the above-mentioned three sections were based on yes or no responses. Oral health-related quality of life (OHRQoL) concerning social, physical, and psychological aspects was evaluated where the question 
was scaled from 1 to 5, ranging from always to none (Appendix). The validity of the questionnaire was ensured through a pilot study on 50 students. The reported ambiguities and feedback were considered based on which the items of the questionnaire were revised. The data for the developed questionnaire was collected before providing the intervention and after 3 weeks of the intervention. The same questionnaire was used to collect data both before the intervention and after 3 weeks of intervention. The time of 3 weeks is considered as it is found appropriate for deriving accurate intervention outcomes (Gartenmann et al., 2017). The reason for selecting this time-period is because previous studies, using the same intervention duration, were able to derive reliable findings (Gartenmann et al., 2017; Lin et al., 2019).

\subsection{Data Analysis}

Statistical Package for Social Sciences (SPSS) Version 20.0 (IBM Corp., Armonk, NY, USA) used for the analysis of collected data. Descriptive statistical tests were used for presenting categorical data, while the ANOVA was used for computing the difference between the groups. The significance value was determined at 0.05 .

\section{Results}

The findings show that the oral health knowledge of the participants substantially improved after the intervention. The results of the teacher's group are found to be more significant as compared to the dentists' group based on their frequent interaction and understanding of the students. The no-intervention group presented no substantial changes (Table 1). Significant changes were observed in the adequate method and changing frequency as well as the consumption of healthy food.

Table 1. Oral Health $(\mathrm{OH})$ Knowledge among the Groups (\%)

\begin{tabular}{lllllll}
\hline \multirow{2}{*}{ Items } & \multicolumn{2}{c}{ Teachers Group } & \multicolumn{2}{c}{ Dentists Group } & \multicolumn{2}{l}{ No intervention Group } \\
\cline { 2 - 7 } & Before & After & Before & After & Before & After \\
\hline Benefit of frequently brushing my teeth & 46.5 & 53.5 & 41.5 & 52.5 & 43.5 & 49.5 \\
Adequate method for tooth brushing & 12.2 & $73.10^{\mathrm{a}}$ & 22.2 & 69.2 & 15.2 & 18.12 \\
Changing my toothbrush frequently & 37.4 & 66.6 & 47.2 & $56.6^{\mathrm{a}}$ & 34.1 & 63.3 \\
Healthy snacks food as a part of my oral health & 46.6 & 86.6 & 57.7 & $96.6^{\mathrm{a}}$ & 47.6 & 54.6 \\
Healthy snacks and drinks are part of my oral health & 34.0 & 66.6 & 32.2 & 56.6 & 33.6 & 39.2 \\
Dentist Visit Time & 45.1 & 62.6 & 35.1 & 62.6 & 41.1 & 52.1 \\
\hline
\end{tabular}

${ }^{* a}$ represents $\mathrm{p}<0.001$.

The results in Table 2 show that the health behavior of the participants improved after the intervention by both the teachers and dentists. The results show that the major improvements were in the understanding of the frequency of the tooth brushing, method of brushing, and less consumption of the food items.

Table 2. Oral Health (OH) Behavior among the Groups (\%)

\begin{tabular}{lllllll}
\hline \multirow{2}{*}{ Items } & \multicolumn{2}{l}{ Teachers Group } & \multicolumn{2}{c}{ Dentists Group } & \multicolumn{2}{c}{ No intervention Group } \\
\cline { 2 - 7 } & Before & After & Before & After & Before & After \\
\hline Frequently toothbrush & 68 & $73 \mathrm{a}$ & 45.2 & 65.1 & 47.0 & 53.1 \\
Fluoridated toothpaste use & 32 & 49.1 & 47.0 & 59.9 & 31.1 & 39.7 \\
Horizontal brushing Technique & 40.3 & 52.6 & 36.7 & $66.3 \mathrm{a}$ & 54.1 & 63.2 \\
Circular motion of the toothbrush technique & 43.9 & $76.5 \mathrm{a}$ & 8.4 & 37.1 & 8.4 & 19.32 \\
Dental floss use & 52.6 & 77.5 & 22.4 & 55.3 & 34.5 & 51.4 \\
Less consumption of the sugary items & 33.0 & $87.9 \mathrm{a}$ & 51.3 & $84.2 \mathrm{a}$ & 30.7 & 49.1 \\
\hline
\end{tabular}

\footnotetext{
${ }^{* \mathrm{a}}$ represents $<0.001$.
} 
Table 3 presents the results for the close-ended questions, which showed that teacher intervention group and dentist intervention group had better oral health after the intervention, as evident from the achieved values.

Table 3. Oral Health $(\mathrm{OH})$ Self-Evaluation among the Groups (\%)

\begin{tabular}{lllllll}
\hline \multirow{2}{*}{ Items } & \multicolumn{2}{l}{ Teachers Group } & \multicolumn{2}{l}{ Dentists Group } & \multicolumn{2}{l}{ No intervention Group } \\
\cline { 2 - 7 } & Before & After & Before & After & Before & After \\
\hline Dental disease & 68 & $73 \mathrm{a}$ & 45.2 & 65.1 & 47.0 & 53.1 \\
Chewing Habit & 32 & 49.1 & 47.0 & 59.9 & 31.1 & 39.7 \\
Oral health practices are good & 40.3 & $84.2 \mathrm{a}$ & 36.7 & $76.5 \mathrm{a}$ & 55.3 & 63.2 \\
\hline
\end{tabular}

${ }^{* a}$ represents $<0.001$.

Table 4 shows that the OHRQoL score for the students, which depicts the best scores for the teacher intervention group as they were able to better integrate with the children. The use of different props and tools might have also facilitated the improved score. The results of the dental group were also better; however, these were less effective as compared to the teachers' group. Limited improvement was found for the no intervention group.

Table 4. OHRQoL

\begin{tabular}{lllll}
\hline \multirow{2}{*}{ Items } & \multicolumn{2}{l}{ Teacher Group } & Dentist Group & No Intervention Group \\
\cline { 2 - 5 } & Mean \pm S. D & Mean \pm S. D & Mean \pm S. D & 0.019 \\
\hline Psychological & $9.20(1.44)$ & $9.18(1.65)$ & $5.23(0.11)$ & 0.076 \\
Physical & $5.68(0.34)$ & $5.21(0.32)$ & $3.99(1.65)$ & 0.026 \\
Social & $0.93(1.61)$ & $0.71(1.54)$ & $1.01(1.01)$ & \\
\hline
\end{tabular}

\section{Discussion}

The study used an observational study design to assess the effectiveness of the school-based OH intervention in Saudi Arabia. The findings of the study showed that the school-based $\mathrm{OH}$ intervention was effective in improving the primary student's health behavior, and their health knowledge. These findings are endorsed by various researches conducted in different regions. For instance, the research of Alsumait et al. (2019) on the Kuwaiti primary students showed that oral health programs at an early age help induce effective oral hygiene practices. Similarly, another study of Ahmad (2019) also endorses school as an effective place for teaching oral health care practices.

A comparison of the teachers and dental groups in the study showed that both the groups were effective and contributed to the improved $\mathrm{OH}$ understanding among the children. This may account for the fact that these children are at an early stage of their life, where forming healthy habits is easier as compared to a later age (Mota, Oswal, Sajnani, \& Sajnani, 2016). This also helps to expand the knowledge at a broader level such as the families of the children as well as the community members. These results are in-line with the earlier researches which reported that improved the oral health behavior of the young children after the intervention (Alsubaie, 2019; Halawany et al., 2018). Angelopoulou et al., (2015) reported that these interventions are useful irrespective of the material used. The findings of the study showed that teacher delivered intervention was more effective as compared to the dentist. These are contrary to the reporting of Reinhardt et al., (2009) which showed no improvement in oral health for the dentist delivered school intervention. It is believed that the OHE status increases with the increase in the educational status, as indicated in the present study.

\subsection{Study Limitations}

Despite the significant contribution of the study for improved $\mathrm{OH}$ knowledge and behavior, some limitations are observed. This includes the selection of the participants such as their gender, age, and region. Also, the study design serves as another limitation, where inclusion of the sample from a diverse population group would have provided concrete results. Also, the interviews with the teachers and dentists concerning the education intervention could have helped improve the results. 


\subsection{Implications for future research}

The findings of the study further recommended that these interventions should be continued to maintain improved $\mathrm{OH}$ status and OHRQoL scores. Such as the schools should introduce hands-on exercises for the students where they are asked to practice brushing and losing. This not only helps to correct the way but also helps motivate them for practicing good $\mathrm{OH}$ practices. Another way is to reinforce oral health education among children. This includes introducing or assimilating different oral health educational courses or chapters in the syllabus or school textbooks. Accordingly, the parents' education level should also be studied as it is a prime determiner of the $\mathrm{OH}$ knowledge and behavior among the children. Thereby, the parents of the children should also be included in the educational intervention or provided different printed oral health education materials.

Future researches are suggested to investigate the experience and challenges which the dentists and the teachers faced while executing the education intervention. The use of longitudinal study design is also suggested to help provide insights on the $\mathrm{OH}$ educational intervention practices that are effective in the long-run.

\section{Conclusion}

The study assessed the school-based intervention outcomes concerning the $\mathrm{OH}$ status among the primary female students in Madinah, Saudi Arabia. Using an observational study design, and a close-ended questionnaire. The findings showed that oral health program is effective in promoting effective $\mathrm{OH}$ practices at an early stage. The comparison of the teacher-based intervention and dentist-based intervention showed improvements, however, the teacher-based intervention was found to be more effective. This may be due to the use of additional material and PowerPoint slides. The finding suggests a positive impact of a school-based intervention on the children's oral health and knowledge. It is suggested that different on-going assessments of the students should be held for promoting improved $\mathrm{OH}$ behaviors and knowledge.

\section{Acknowledgments}

The author is very thankful to all the associated personnel in any reference that contributed in/for the purpose of this research.

\section{Funding}

This research received no external funding.

\section{Competing Interests Statement}

The authors declare that there are no competing or potential conflicts of interest.

\section{References}

Adair, P., Burnside, G., \& Pine, C. (2013). Analysis of health behaviour change interventions for preventing dental caries delivered in primary schools. Caries Res, 47(Suppl. 1), 2-12. https://doi.org/10.1159/000351829

Ahmad, M. (2019). Effectiveness of Health Education to Improve Oral Care of Primary School Children in a Rural Community of Pakistan. EC Dent Sci, 18, 01-09.

Al-Banyan, R., Echeverri, E., Narendran, S., \& Keene, H. (2000). Oral health survey of 5-12-year-old children of National Guard employees in Riyadh, Saudi Arabia. Int $J$ Clin Pediatr Dent, 10(1), 39-45. https://doi.org/10.1046/j.1365-263x.2000.00166.x

Al-Rafee, M. A., AlShammery, A. R., AlRumikan, A. S., \& Pani, S. C. (2019). A comparison of dental caries in urban and rural children of the Riyadh Region of Saudi Arabia. Frontiers in public health, 7. https://doi.org/10.3389/fpubh.2019.00195

Alsubaie, A. S. R. (2019). Oral health-related behaviors and dental pain among children in Saudi Arabia. Int J Dent Oral Health, 11(1), 1. https://doi.org/10.4103/jioh.jioh_253_18

Alsumait, A., ElSalhy, M., Behzadi, S., Raine, K. D., Gokiert, R., Cor, K., . . Amin, M. (2019). Impact evaluation of a school-based oral health program: Kuwait National Program. BMC oral health, 19(1), 202. https://doi.org/10.1186/s12903-019-0895-1

Alswat, K., Mohamed, W. S., Wahab, M. A., \& Aboelil, A. A. (2016). The association between body mass index and dental caries: cross-sectional study. Journal of clinical medicine research, 8(2), 147. https://doi.org/10.14740/jocmr2433w

Angelopoulou, M. V., Kavvadia, K., Taoufik, K., \& Oulis, C. J. (2015). Comparative clinical study testing the effectiveness of school based oral health education using experiential learning or traditional lecturing in 10 year-old children. BMC oral health, 15(1), 51. https://doi.org/10.1186/s12903-015-0036-4 
BaniHani, A., Deery, C., Toumba, J., Munyombwe, T., \& Duggal, M. (2018). The impact of dental caries and its treatment by conventional or biological approaches on the oral health-related quality of life of children and carers. Int J Clin Pediatr Dent, 28(2), 266-276. https://doi.org/10.1111/ipd.12350

CDC. (2020). Oral Health. Working to Improve Oral Health for All Americans at a Glance. 2016.

Craig, S. A., Baker, S. R., \& Rodd, H. D. (2015). How do children view other children who have visible enamel defects? Int J Clin Pediatr Dent, 25(6), 399-408. https://doi.org/10.1111/ipd.12146

de Castilho, A. R. F., Mialhe, F. L., de Souza Barbosa, T., \& Puppin-Rontani, R. M. (2013). Influence of family environment on children's oral health: a systematic review. J Pediatr (Rio J), 89(2), 116-123. https://doi.org/10.1016/j.jped.2013.03.014

Deinzer, R., Cordes, O., Weber, J., Hassebrauck, L., Weik, U., Krämer, N., . . Margraf-Stiksrud, J. (2019). Toothbrushing behavior in children-an observational study of toothbrushing performance in 12 year olds. BMC oral health, 19(1), 1-9. https://doi.org/10.1186/s12903-019-0755-z

Farooqi, F. A., Khabeer, A., Moheet, I. A., Khan, S. Q., \& Farooq, I. (2015). Prevalence of dental caries in primary and permanent teeth and its relation with tooth brushing habits among schoolchildren in Eastern Saudi Arabia. Saudi Med J, 36(6), 737. https://doi.org/10.15537/smj.2015.6.10888

Gartenmann, S. J., Dörig, I., Sahrmann, P., Held, U., Walter, C., \& Schmidlin, P. R. (2017). Influence of different post-interventional maintenance concepts on periodontal outcomes: an evaluation of three systematic reviews. BMC oral health, 17(1), 19. https://doi.org/10.1186/s12903-016-0244-6

Halawany, H. S., Al Badr, A., Al Sadhan, S., Al Balkhi, M., Al-Maflehi, N., Abraham, N. B., . . Al Sherif, G. (2018). Effectiveness of oral health education intervention among female primary school children in Riyadh, Saudi Arabia. Saudi Dent J, 30(3), 190-196. https://doi.org/10.1016/j.sdentj.2018.04.001

Hazra, A., \& Gogtay, N. (2016). Biostatistics series module 5: Determining sample size. Indian J Dermatol, 61(5), 496. https://doi.org/10.4103/0019-5154.190119

Lin, J.-H., Huang, Y.-K., Lin, K.-D., Hsu, Y.-J., Huang, W.-F., \& Huang, H.-L. (2019). Randomized Controlled Trial on Effects of a Brief Clinical-Based Intervention Involving Planning Strategy on Self-Care Behaviors in Periodontal Patients in Dental Practice. Int $J$ Environ Res Public Health, 16(20), 3838. https://doi.org/10.3390/ijerph16203838

Mota, A., Oswal, K. C., Sajnani, D. A., \& Sajnani, A. K. (2016). Oral health knowledge, attitude, and approaches of pre-primary and primary school teachers in Mumbai, India. Scientifica, 2016. https://doi.org/10.1155/2016/5967427

Nguyen, T. T., Nguyen, B. B. T., Nguyen, M. S., Olak, J., \& Saag, M. (2016). Effect of School Oral Health Promotion Programme on dental health and health behaviour in Vietnamese schoolchildren. Pediatr Dent $J$, 26(3), 115-121. https://doi.org/10.1016/j.pdj.2016.09.001

Organization, W. H. (2020). Centers for Disease Control and Prevention (CDC. Global school-based student health survey (GSHS).

Reinhardt, C. H., Löpker, N., Noack, M. J., Klein, K., \& Rosen, E. (2009). Peer tutoring pilot program for the improvement of oral health behavior in underprivileged and immigrant children. Pediatr Dent, 31(7), 481-485.

Suresh, S. (2014). Nursing research and statistics. Elsevier Health Sciences.

Tinanoff, N. (2017). Individuals who brush their teeth infrequently may be at greater risk for new carious lesions. Journal of Evidence Based Dental Practice, 17(1), 51-52. https://doi.org/10.1016/j.jebdp.2017.01.010

Villanueva-Vilchis, M. d. C., Aleksejūnienè, J., \& López-Núñez, B. (2019). A peer-led dental education program for modifying oral self-care in Mexican children. salud pública de méxico, 61, 193-201. https://doi.org/10.21149/9273

WMA. (2019). WMA Declaration of Helsinki - Ethical Principles for Medical Research Involving Human Subjects.

Zhang, S., Xu, B., Liu, J., Lo, E. C., \& Chu, C.-H. (2015). Dental and periodontal status of 12-year-old Dai school children in Yunnan Province, China: a cross-sectional study. BMC oral health, 15(1), 117. https://doi.org/10.1186/s12903-015-0106-7 


\section{Appendix}

\section{Questionnaire}

Table A1. Children Oral Health (OH) Status

\begin{tabular}{|c|c|c|c|}
\hline S.no & OH Knowledge & Yes & No \\
\hline 1. & I know the benefit of frequently brushing my teeth. & & \\
\hline 2. & I know the adequate method for toothbrushing. & & \\
\hline 3. & $\begin{array}{l}\text { I know the benefit of changing my toothbrush } \\
\text { frequently. }\end{array}$ & & \\
\hline 4. & $\begin{array}{l}\text { I know that consumption of healthy snacks food as a } \\
\text { part of my oral health. }\end{array}$ & & \\
\hline 5. & $\begin{array}{l}\text { I know that consumption of healthy snacks drinks is } \\
\text { part of my oral health. }\end{array}$ & & \\
\hline 6. & I know the benefit of frequently visit dentists. & & \\
\hline S.no & OH Behavior & Yes & No \\
\hline 1. & I frequently toothbrush. & & \\
\hline 2. & I frequently use fluoridated toothpaste. & & \\
\hline 3. & I use horizontal brushing technique. & & \\
\hline 4. & I use the circular motion of the toothbrush technique. & & \\
\hline 5. & I use dental floss. & & \\
\hline 6. & I consume sugary items & & \\
\hline S.no & OH Self-Evaluation & Yes & No \\
\hline 1. & I have dental disease. & & \\
\hline 2. & I have chewing habit & & \\
\hline 3. & My oral health practices are good & & \\
\hline
\end{tabular}

Table A2. Oral health-related quality of life (OHRQoL)

Always Regularly Sometimes $\begin{aligned} & \text { Most of the None } \\ & \text { Time }\end{aligned}$

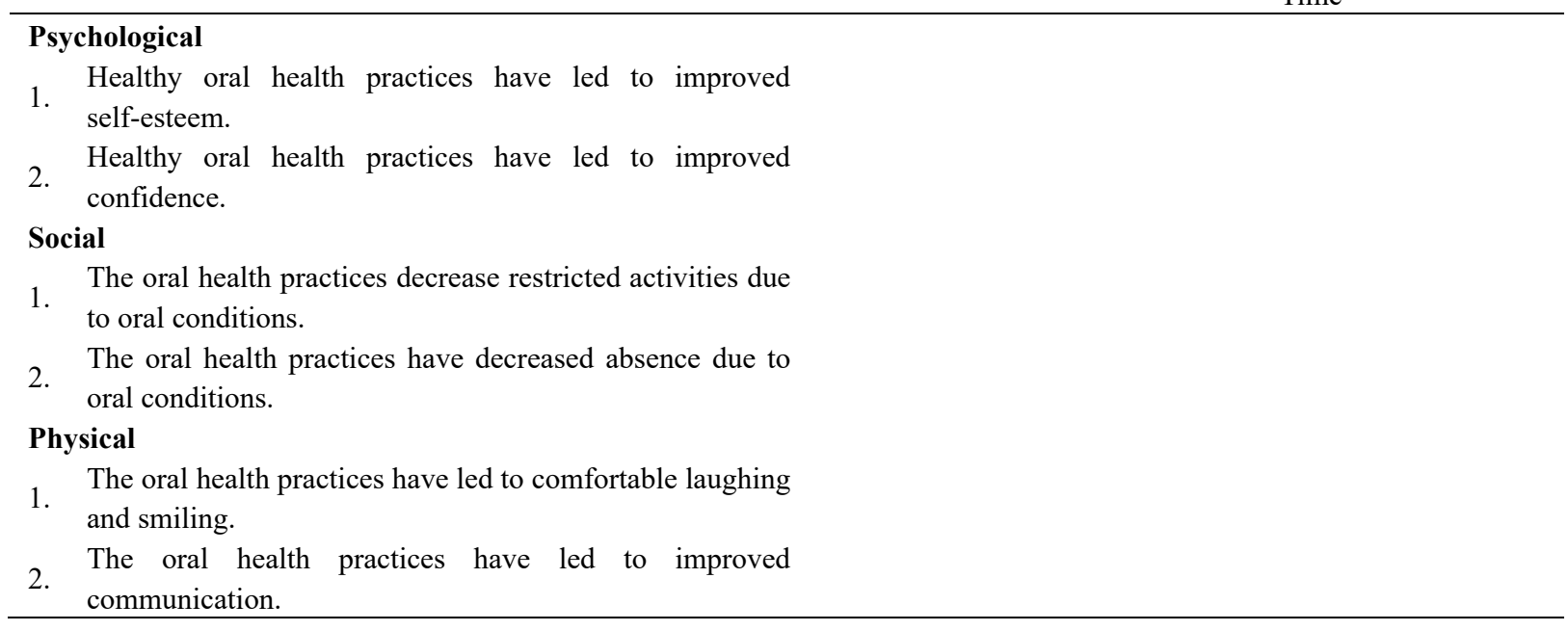

\section{Copyrights}

Copyright for this article is retained by the author(s), with first publication rights granted to the journal.

This is an open-access article distributed under the terms and conditions of the Creative Commons Attribution license (http://creativecommons.org/licenses/by/4.0/). 